\title{
Editorial Expression of Concern: Tumor necrosis factor-inducible gene 6 protein ameliorates chronic liver damage by promoting autophagy formation in mice
}

Sihyung Wang, Chanbin Lee, Jieun Kim, Jeongeun Hyun, Minso Lim, Hyuk-Jin Cha, Seh-Hoon Oh,

Yung Hyun Choi and Youngmi Jung

The Editor-in-Chief is issuing an editorial Expression of Concern to alert readers that the Committee of Research Integrity of Pusan University has found that Minso Lim, the fifth author listed on this article ${ }^{1}$, did not participate in the study described. Yung Hyun Choi has stated that Minso Lim should be included in the authorship. None of the other authors has responded to emails from the Editor or the Publisher.
Received: 7 December 2020 Accepted: 15 December 2020.

Published online: 22 February 2021

\section{Reference}

1. Wang, S. et al. Tumor necrosis factor-inducible gene 6 protein ameliorates chronic liver damage by promoting autophagy formation in mice. Exp Mol Med 49, e380, https://doi.org/10.1038/emm.2017.140 (2017). 